\title{
Deal a death blow! HCC in cirrhotics - thrombotic complications: their frequency, characteristics, and risk factors
}

\author{
Khalid Mahmood ${ }^{1}$, Iftikhar Haider Naqvi ${ }^{1}$, Aamer Mahmood ${ }^{2}$, Syed Muhammad ${ }^{1}$, Noor Muhammad ${ }^{3}$ \\ ${ }^{1}$ Department of Medicine, Dow University of Health Sciences, Karachi, Pakistan \\ ${ }^{2}$ Agha Khan University Hospital, Karachi, Pakistan \\ ${ }^{3}$ Department of Oncology, Dow University of Health Sciences Karachi, Pakistan
}

Gastroenterology Rev 2018; 13 (1): 52-60

DOI: https://doi.org/10.5114/pg.2018.74566

Key words: hepatocellular carcinoma, tumour thrombosis, cirrhosis.

Address for correspondence: Dr. Iftikhar Haider Naqvi, Department of Medicine, Dow University of Health Sciences, Baba-e-Urdu Road, 74200 Karachi, Pakistan, phone: +92 21 36647077, e-mail: drihnaqvi@gmail.com

\begin{abstract}
Introduction: The hepatocellular carcinoma (HCC), being the commonest primary cancer, holds the sixth slot in the list of common cancers worldwide. Thrombotic complications in the form of portal vein tumour thrombosis (PVTT) and bland portal vein thrombosis with HCC are common with a bad prognosis.

Aim: The study aims to determine the demographic, clinical, and biochemical parameters of HCC patients. The study also compares the clinical and biochemical parameters among patients having HCC with and without thrombotic complication. It further aims to assess the risk factors for thrombotic complication.

Material and methods: This was a retrospective study with a cross sectional design. Clinical and biochemical parameters among patients having HCC with and without thrombotic complication were determined. Tests of statistical significance were applied where a $p$-value $<0.05$ was statistically significant

Results: Overall 118/305 (38.7\%) patients of HCC had thrombotic complications. Most of the patients (74.5\%) had PVTT whereas in $25.5 \%$ bland PVT was found. Higher age, male gender, greater tumour size, advanced stage of HCC (Okuda II, III), multifocal/massive tumour morphology and presence of oesophageal varices, upper GI bleeding, ascites and hepatic encephalopathy, and extrahepatic spread were found to be statistically significant for thrombotic complication ( $p<0.05$ for each).

Conclusions: Viral related HCC is a commonly reported problem. Thrombotic complication is mainly due to tumour thrombosis rather than bland portal vein thrombosis. Age, gender, greater tumour size, advanced stage of HCC (Okuda II, III), and multifocal/ massive tumour morphology were important risk factors for thrombotic complication.
\end{abstract}

\section{Introduction}

The hepatocellular carcinoma (HCC), being the commonest primary cancer, holds the sixth slot in the list of common cancers worldwide. Among cancer-attributed mortality, the third slot is held by HCC itself internationally [1], where around 700,000 deaths are annually linked to HCC alone [2, 3]. Despite the advancement in the management of cirrhosis, $\mathrm{HCC}$ rates are still rising [4]. Around $80 \%$ of HCC cases have been reported from South-East Asia and Africa [5, 6]. Viral-related chronic hepatitis B (HBV) and C (HCV) by and large are shown as highlighted risk factors for HCC in Asians [7, 8]. The reported prevalence of non-viral HCC, which includes autoimmune hepatitis, metabolic liver diseases, alcoholic liver injury and aflatoxins, ranges between $5 \%$ and $15 \%$ [8].

Hepatocellular carcinoma during its progression has been related to marked neo angiogenesis. Primitively, the tumour has scanty blood supply, mainly from the portal vein. Conversely, on further growth of the tumour it also establishes its blood supply from newly formed arteries. Thrombotic complication of HCC is in two forms, where one is the direct invasion of tumour to portal circulation (PVTT) and the second is bland portal vein thrombosis (PVT). Hepatocellular carcinoma stag- 
ing, prognosis, and treatment options are affected by portal vein tumour thrombus, which is considered as an important determinant for the overall clinical course of $\mathrm{HCC}[9,10]$. Portal vein tumour thromboses with HCC increases the chances of resurgence of the tumour, which minimises the aggressive treatment options like trans-arterial chemoembolisation (TACE), tumour resection, and even liver transplantation. The limited treatment options further reduce the survival in $\mathrm{HCC}$ with PVTT.

The reported frequency of PV invasion in patients with HCC is $11 \%$ to $42 \%[11,12]$. The PVTT with HCC is a common complication related with a bad prognosis. A conjoint presentation of PVT along with HCC was previously observed in $10 \%$ to $40 \%$ of patients [13]. Former studies have shown better survival in HCC patients without thrombotic complication in comparison to subjects having HCC with portal vein thrombosis $[12,14]$. The worst prognostic outcome is seen in PVTT in patients of HCC because it may ensue extensively disseminated tumours within the liver compromising it gravely.

Pakistan is positioned in the intermediate zone for prevalence of viral-related chronic hepatitis B and C [5]. The published studies in Pakistan on HCC patients are mainly based on demographic and clinical profile. Earlier studies on Pakistani patients disclosed chronic HCV as the most widespread aetiology of HCC along with chronic HBV $[5,15,16]$. Pakistan is a country with limited health resources where limited treatment options for HCC (inclusive of liver transplantation) are available, so more comprehensive data, particularly with thrombotic complication (PVTT, bland PVT), on HCC are needed.

This study shall include, as well as demographic and clinical profile, thrombotic complication (PVT, PVTT) and its risk factors, which are important devisors for treatment selection and overall survival. This study would help in devising a comprehensive and concrete strategy to manage HCC in Pakistan.

\section{Aim}

The study aimed to:

1) Determine the demographic, clinical, and biochemical parameters of HCC patients.

2) Compare the clinical and biochemical parameters among patients having HCC with and without thrombotic complication.

3) Assess the risk factors for thrombotic complication among HCC patients.

\section{Material and methods}

This was a retrospective study with a cross sectional design. Patient's aged $\geq 16$ years, either previously or recently diagnosed with HCC, admitted in the medical department of Civil Hospital Karachi from 2010 to 2015 were registered in the study. The demographic information along with causes, and clinical and biochemical details of patients suffering from HCC were recorded. On the basis of radiological details, two groups of patients were assorted: one with thrombotic complications and the other without thrombotic complications. All Cases with incomplete information were excluded.

\section{Cirrhosis}

Cirrhosis was confirmed on clinical (stigmata of chronic liver disease), biochemical, and radiological (abdominal ultrasound or computerised tomography parameters). Radiological features demonstrated small shrunken liver and intra-abdominal varices with or without enlarged spleen. Cirrhosis was also confirmed on a histopathological basis, wherever required [17]. Cirrhosis was assessed and staged for its severity in accordance with Child-Pugh classification [18].

\section{Hepatocellular carcinoma}

Confirmation of HCC was done by using advanced imaging, either three-phase computerised tomography (CT) scan or magnetic resonance imaging (MRI). Hepatocellular carcinoma was also confirmed alternatively on CT scan/MRI findings by the detection of contrast hyperenhancement in the arterial phase (wash-in) and hypoenhancement in the portal venous and/or delayed phases of acquisition (wash-out), in patients with the setting of chronic liver disease (with or without histopathological evidence) [19].

\section{Staging and classification of hepatocellular carcinoma}

All enrolled cases of HCC were staged in accordance with the Okuda system of staging [20]. Classification of HCC was done on morphological grounds, which included size and number of nodules. Hepatocellular carcinoma classified as solitary, paucifocal (having three or less than three nodules), multifocal (having more than three nodules), and massive or infiltrative (large mass with undefined margins with size of $>10 \mathrm{~cm}$ ) [21].

\section{Thrombotic complication of hepatocellular carcinoma}

Portal vein thrombosis was labelled as "bland" on contrast-enhanced images during the portal venous phase when the lumen of the vessel was partially or completely obstructed, as shown by a filling defect. The signal intensity of filling defect is less than which the tumour displays. The PVTT was diagnosed 
in accordance with criteria by Shah et al. [22], whereas a "malignant" thrombus was labelled when one of the underlying criteria was fulfilled.

1. Spreading of the involved vessel

Main portal vein vascular diameter $\geq 1.8 \mathrm{~cm}$, right portal vein diameter $\geq 1.6 \mathrm{~cm}$, left portal vein diameter $\geq 1.8 \mathrm{~cm}$, and disproportionate increase when compared within same lobe with normal same-order portal vein tributaries [22].

2. Obvious augmentation on dynamic contrast $C T$ or $M R$ images during arterial phase [23].

\section{Biochemical parameters}

All biochemical tests related to cirrhosis of liver were recorded. Serum bilirubin, total protein, serum

Table I. Demographic characteristics of patients with HCC

\begin{tabular}{|c|c|c|}
\hline Profile of patients & $\begin{array}{c}\text { No. of } \\
\text { patients with } \\
\text { HCC }(n=305)\end{array}$ & Frequency (\%) \\
\hline Age & $46.2 \pm 16$ & \\
\hline \multicolumn{3}{|l|}{ Gender: } \\
\hline Male & 186 & 60.98 \\
\hline Female & 119 & 39.02 \\
\hline \multicolumn{3}{|l|}{ Aetiology: } \\
\hline Viral related: & 280 & 91.80 \\
\hline HCV alone & 148 & 48.52 \\
\hline HBV alone & 97 & 31.8 \\
\hline $\mathrm{HCV}+\mathrm{HBV}$ & 22 & 7.21 \\
\hline $\mathrm{HBV}+\mathrm{HDV}$ & 13 & 4.26 \\
\hline Non-viral related: & 25 & 8.2 \\
\hline Alcohol & 11 & 3.6 \\
\hline Others & 14 & 4.6 \\
\hline HCC with underlying cirrhosis & 288 & 94.5 \\
\hline \multicolumn{3}{|l|}{ Severity of cirrhosis: } \\
\hline CTP-A & 31 & 10.8 \\
\hline CTP-B & 121 & 42 \\
\hline CTP-C & 136 & 47.2 \\
\hline HCC without underlying & 17 & 5.5 \\
\hline \multicolumn{3}{|l|}{ Cirrhosis: } \\
\hline Incidental HCC & 19 & 6.3 \\
\hline Symptomatic HCC & 286 & 93.7 \\
\hline
\end{tabular}

albumin, prothrombin time (PT), and transaminases (ALT \& AST) were all noted. Viral markers anti-HCV and HBsAg were recorded. Tumour marker $\alpha$-fetoprotein (AFP) was also recorded.

\section{Statistical analysis}

Means with standard deviations were presented for the continuous variables and analysed by student's $t$-test. The categorical variables were analysed for two or more groups by $\chi^{2}$ test with Yates's correction. An $\alpha$ value of $<0.05$ was considered to be a statistically significant cut-off.

\section{Results}

\section{Demographic profile}

A total of 399 HCC patients who had been admitted to the medical department of the Civil Hospital of Karachi were identified through retrospective record analysis from 2010 to 2015. Out of 399 patients, 305 who fulfilled the eligibility criteria were registered for the study. The demographic summary of the patients is given in Table I. In this study the majority (61\%) of patients were male. The mean patient age was $46.2 \pm 16$ years. The main cause of HCC was viral related $(91.8 \%)$, where most of the patients had chronic HCV (48.52\%) followed by chronic HBV (31.8\%). Co-infections with HBV and HCV were found in $7.21 \%$ of patients. Co-infection with chronic HBV and HDV were found in $4.26 \%$ of patients. Twenty-five (8.2\%) patients had non-viral causes (alcohol and others) of HCC. The majority (92.5\%) of patients had full-blown underlying cirrhosis at the time of diagnosis. Most of the cirrhotics had severe liver disease CTP-C (47.2\%) followed by CTP-B (42\%) and CTP-A (10.8\%). Incidental HCC was found only in $6.3 \%$, while the majority (93.7\%) had symptomatic HCC. Demographic profiles are shown in Table I.

\section{Tumour characteristics}

Tumour characteristics are shown in Table II. In most $(46.2 \%)$ of the patients, the tumour size was $5-10 \mathrm{~cm}, 30.8 \%$ of patients had tumour size $<5 \mathrm{~cm}$, and $23 \%$ of patients had tumour size $>10 \mathrm{~cm}$. On a morphologic basis, most of the patients had multi-focal (32.2\%) lesions, followed by solitary $(27.0 \%)$ and paucifocal $(20.7 \%)$. The infiltrative lesions were found in $19.6 \%$ of cases. Hepatocellular carcinoma lesions were distributed mainly (61.9\%) in the right lobe, $13.7 \%$ had lesions in the left lobe, and $22.4 \%$ of patients had lesions in both lobes. The majority (55.7\%) of patients had Okuda stage II followed by stage III (32.1\%) and stage I (12.2\%), respectively. Two hundred and sixty-eight patients (87.8\%) with HCC had advanced cancer, i.e. Okuda stage II and III. 


\section{Thrombotic complication}

Thrombotic complication was documented in 118 (38.7\%) patients. Most of the patients (74.5\%) had PVTT, whereas in $25.5 \%$ bland PVT was found. PVTT was found in various tributaries of the portal vein. Mostly $(46.5 \%)$ thrombus was found in the major trunk of the portal vein (MPV). In $22.8 \%$ of patients, the right portal vein (RPV) was involved, followed by $11.5 \%$ of patients with left portal vein (LPV) involvement. The RPV and LPV were involved in $10.2 \%$ of patients. Inferior vena cava with portal vein was involved in $6.8 \%$ of patients. Splenic vein (SP) and superior mesenteric vein (SMV) were involved in $2.2 \%$ of patients. Thrombotic complications of HCC are also shown in Table II.

\section{Complications and laboratory parameters}

All important underlying complications of cirrhosis and laboratory parameters were assessed and compared in both groups as shown in Table III. The majority biochemical parameters (except ALT and AST) were statistically significantly deranged in HCC patients with bland portal venous thrombosis and portal vein tumour thrombosis compared to HCC without thrombotic complication as demonstrated by Student's $t$-test ( $p$-value $<0.0001)$.

Regarding the association of accompanying complications with thrombotic complication, oesophageal varices, upper GI bleeding, ascites and hepatic encephalopathy, and extra hepatic spread were found to be more common in HCC with thrombotic complication versus that without thrombotic complication $\left(\chi^{2} p\right.$-value $<0.05)(p=0.28)$.

\section{Risk factors for thrombotic complication in hepatocellular carcinoma}

Table IV shows the various risk factors considered to have a significant association with thrombotic complication in HCC patients. Age, gender, greater tumour size and multifocal/massive tumour morphology, advanced stages of HCC (Okuda II, III), and cirrhosis (CTP-B, C) were found to be statistically significant for thrombotic complication among HCC patients ( $p<0.05$ for each). Aetiology for viral versus non-viral was tested as a risk factor for thrombotic complication and found to be insignificant.

\section{Discussion}

Hepatocellular carcinoma is a primary concern the world over. This is the first study in Pakistan, carried out for comparison of clinical, biochemical, and complications of underlying cirrhosis among patients of
Table II. Tumour characteristics of hepatocellular carcinoma

\begin{tabular}{lcc} 
Tumour characteristics & $\begin{array}{c}\text { No. of } \\
\text { patients with } \\
\text { HCC }(n=305)\end{array}$ & Frequency (\%) \\
\hline Tumour size $[\mathrm{cm}]:$ & & \\
\hline$<5$ & 94 & 30.8 \\
\hline $5-10$ & 141 & 46.2 \\
\hline$>10$ & 70 & 23 \\
\hline
\end{tabular}

\begin{tabular}{lcc}
\hline Morphologic types: & & \\
\hline Solitary & 84 & 27.5 \\
\hline Paucifocal ( $\leq 3$ nodules) & 63 & 20.7 \\
\hline Multifocal (> 3 nodules) & 98 & 32.2 \\
\hline Massive/infiltrative & 60 & 19.6 \\
\hline Distribution of HCC: & 189 & \\
\hline Right & 42 & 13.7 \\
\hline Left & 74 & 24.3 \\
\hline Both &
\end{tabular}

Stages of HCC:

Okuda:

\begin{tabular}{lcc}
\hline I & 37 & 12.2 \\
\hline II & 170 & 55.7 \\
\hline III & 98 & 32.1
\end{tabular}

Tumour advancement:

Non-advanced cancer $\quad 166 \quad 12.2$

(Okuda I)

\begin{tabular}{lll}
\hline Advanced cancer & 139 & 87.8
\end{tabular}

(Okuda II, III)

Thrombotic complication:

\begin{tabular}{lcc}
\hline $\begin{array}{l}\text { HCC with thrombotic } \\
\text { complication }\end{array}$ & 118 & 38.7 \\
\hline PVTT (PPVT) & 88 & 74.5 \\
\hline MPV & 41 & 46.5 \\
\hline RPV & 20 & 22.8 \\
\hline LPV & 10 & 11.5 \\
\hline RPV + LPV & 9 & 10.2 \\
\hline PV with IVC & 6 & 6.8 \\
\hline SMV + SP & 2 & 2.2 \\
\hline land portal vein thrombosis & 30 & 25.5
\end{tabular}

$M P V$ - main trunk of portal vein, $R P V$ - right portal vein, $P V$ - portal vein, $I V C$ - inferior vena cava, SMV - superior mesenteric vein, $S P$ - splenic vein. 
Table III. Biochemical parameters and complications of cirrhosis in patients having HCC

\begin{tabular}{|c|c|c|c|}
\hline $\begin{array}{l}\text { Biochemical parameters and } \\
\text { complications related to cirrhosis }\end{array}$ & $\begin{array}{l}\text { HCC with thrombotic complication } \\
\text { (Bland portal vein thrombosis + PVTT) } \\
\qquad \begin{array}{c}N=118(38.7 \%) \\
\text { Mean } \pm \text { SD }\end{array}\end{array}$ & $\begin{array}{l}\text { HCC without thrombotic } \\
\text { complication } \\
N=187(61.3 \%) \\
\text { Mean } \pm \text { SD }\end{array}$ & $\begin{array}{c}\text { Student's } t \text {-test } \\
P \text {-value }\end{array}$ \\
\hline \multicolumn{4}{|l|}{ Biochemical parameters: } \\
\hline Serum albumin [g/dl] & $2.6 \pm 0.6$ & $3.3 \pm 0.3$ & $<0.0001^{*}$ \\
\hline Serum bilirubin [mg/dl] & $11.7 \pm 9.1$ & $4.7 \pm 2.6$ & $<0.0001^{*}$ \\
\hline Serum ALT [U/I] & $660 \pm 316$ & $592 \pm 291$ & 0.060 \\
\hline Serum AST [U/I] & $532 \pm 341$ & $481 \pm 290$ & 0.179 \\
\hline Serum ALP [U/I] & $235 \pm 78.1$ & $166 \pm 44.1$ & $<0.0001^{\star}$ \\
\hline$\alpha$-Fetoprotein [ng/l] & $1382.7 \pm 917.3$ & $372 \pm 200$ & $<0.0001^{\star}$ \\
\hline INR & $1.5 \pm 0.1$ & $1.3 \pm 0.2$ & $<0.0001^{*}$ \\
\hline \multicolumn{4}{|l|}{ Complications related to cirrhosis: } \\
\hline \multicolumn{4}{|l|}{ Oesophageal varices: } \\
\hline Yes & $107(35 \%)$ & $138(45.4 \%)$ & $0.0001^{\star}$ \\
\hline No & $11(3.6 \%)$ & $49(16 \%)$ & \\
\hline \multicolumn{4}{|l|}{ Upper Gl bleeding: } \\
\hline Yes & $90(29.5 \%)$ & $116(38 \%)$ & $0.004^{*}$ \\
\hline No & $28(9.18 \%)$ & $71(23.3 \%)$ & \\
\hline \multicolumn{4}{|l|}{ Ascites: } \\
\hline Yes & $101(33 \%)$ & $140(46 \%)$ & $0.012^{*}$ \\
\hline No & $17(5.6 \%)$ & $47(15.4 \%)$ & \\
\hline \multicolumn{4}{|l|}{ Hepatorenal syndrome: } \\
\hline Yes & $81(26.5 \%)$ & $65(21.3 \%)$ & $<0.0001^{*}$ \\
\hline No & $37(12.1 \%)$ & $122(40 \%)$ & \\
\hline \multicolumn{4}{|l|}{ Hepatic encephalopathy: } \\
\hline Yes & $59(19.4 \%)$ & $119(39 \%)$ & $0.007^{\star}$ \\
\hline No & $29(9.5 \%)$ & $98(32.1 \%)$ & \\
\hline \multicolumn{4}{|l|}{ Hepatopulmonary syndrome: } \\
\hline Yes & $18(5.9 \%)$ & $19(6.2 \%)$ & 0.09 \\
\hline No & $100(32.7 \%)$ & $168(55 \%)$ & \\
\hline \multicolumn{4}{|l|}{ Extra-hepatic spread: } \\
\hline Yes & $62(20.3 \%)$ & $100(32.7 \%)$ & $0.02^{\star}$ \\
\hline No & $56(18.3 \%)$ & $87(28.5 \%)$ & \\
\hline
\end{tabular}

hepatocellular carcinoma with and without thrombotic complication. The age distribution of patients was slightly less than the earlier studies [24, 25], where most of the cases were reported in the fifth to sixth decade of life. The slightly low-age group in this study can be explained by the age-wise incidence of HCC, which may be dependent on the aetiological and geographic factors [26]. 
Table IV. Risk factors for thrombotic complications in HCC patients

\begin{tabular}{|c|c|c|c|}
\hline $\begin{array}{l}\text { Risk factors for thrombotic } \\
\text { complication in HCC }\end{array}$ & $\begin{array}{l}\text { HCC with thrombotic complication } \\
\text { (Bland + tumour portal vein } \\
\text { thrombosis) } \\
N=118(38.7 \%) \\
\text { Mean } \pm \text { SD }\end{array}$ & $\begin{array}{l}\text { HCC without thrombotic } \\
\text { complication } \\
N=187(61.3 \%) \\
\text { Mean } \pm \text { SD }\end{array}$ & $P$-value \\
\hline Age (mean \pm SD) & $49 \pm 14.1$ & $43 \pm 13.6$ & $0.0006^{*}$ \\
\hline \multicolumn{4}{|l|}{ Gender: } \\
\hline Male $(n=186)$ & $61(20 \%)$ & $125(41 \%)$ & $0.028^{\star}$ \\
\hline Female $(n=119)$ & $27(8.9 \%)$ & $92(30.1 \%)$ & \\
\hline \multicolumn{4}{|l|}{ Tumour size: } \\
\hline$<5 \mathrm{~cm}(n=94)$ & $8(2.6 \%)$ & $86(28.3 \%)$ & $<0.0001^{*}$ \\
\hline $5-10 \mathrm{~cm}(n=141)$ & $31(10.2 \%)$ & $110(36.1 \%)$ & \\
\hline$>10 \mathrm{~cm}(n=70)$ & 49 (16\%) & $21(6.8 \%)$ & \\
\hline \multicolumn{4}{|l|}{ Morphology: } \\
\hline Solitary $(n=84)$ & $8(2.6 \%)$ & $76(25 \%)$ & $<0.0001^{*}$ \\
\hline Paucifocal $(n=63)$ & $13(4.3 \%)$ & $50(16.5 \%)$ & \\
\hline Multifocal $(n=98)$ & $23(7.5 \%)$ & 75 (24.5\%) & \\
\hline Massive/infiltrative $(n=60)$ & $44(14.4 \%)$ & $16(5.2 \%)$ & \\
\hline \multicolumn{4}{|l|}{ OKUDA: } \\
\hline I $(n=37)$ & $8(2.6 \%)$ & $29(9.5 \%)$ & $0.001^{*}$ \\
\hline$\|(n=170)$ & $38(12.4 \%)$ & $132(43.3 \%)$ & \\
\hline III $(n=98)$ & $42(13.8 \%)$ & $56(18.4 \%)$ & \\
\hline \multicolumn{4}{|l|}{ CTP $($ total $n=288):$} \\
\hline CTP-A $(n=31)$ & $16(5.5 \%)$ & $15(5.2 \%)$ & $<0.0001^{*}$ \\
\hline CTP-B $(n=121)$ & $21(7.3 \%)$ & $100(34.7 \%)$ & \\
\hline CTP-C $(n=136)$ & $51(17.7 \%)$ & 85 (29.5\%) & \\
\hline \multicolumn{4}{|l|}{ Aetiology: } \\
\hline Viral $(n=280)$ & $82(26.8 \%)$ & $198(64.9 \%)$ & 0.288 \\
\hline Non-viral $(n=25)$ & $6(1.96 \%)$ & $19(6.3 \%)$ & \\
\hline
\end{tabular}

The male preponderance in this study is similar to the previous published study $[25,27]$. The majority (94.5\%) of the patients in our study had established cirrhosis of viral aetiology. HCV was the commonest (52.85\%) aetiology, followed by HBV (34.\%), and most of the underlying cirrhotics had severe liver disease CTP-C (47.2\%). A large earlier native study also showed the same pattern of cirrhosis, its severity, and aetiology [28]. The majority of patients (93.7\%) had symptomatic hepatocellular carcinoma in this study, which is congruent to earlier published studies [28, 29].
Hepatocellular carcinomas patients at their preliminary stage usually stay asymptomatic and are revealed in most cases by sporadic surveillance. Hepatocellular carcinoma, when diagnosed at symptomatic stage, has increased risk of advanced disease with worst prognosis. Most of the patients in this study had Okuda stage II and III hepatocellular carcinoma, which is in accordance with previous studies [4, 28-30]. Tumour size and the morphologic types of HCC in this study are similar to a previously published local study [28]. The multifocal (32.2\%) and massive/infiltrative (19.6\%) types of HCC were also present in this study. Demirjian et al. [31] 
reported slightly lower frequency (7-13\%) of infiltrative massive tumour in their study. Tumour size of 5$10 \mathrm{~cm}$ was found in most of the patients, whereas only $19.6 \%$ had size $>10 \mathrm{~cm}$. The tumour size variation in this study is also similar to earlier reported studies [28, 29]. The distribution of HCC in this study was in agreement with earlier studies, where most of the lesions were found in the right lobe, both in right and left lobes, and left lobe alone, respectively [28, 29, 32]. Thrombotic complication in HCC is of paramount importance because for overall survival of HCC, PVTT is considered to be an independent predictor. About a 118 (38.7\%) patients had thrombotic complication among HCC, where the majority had PVTT followed by bland portal vein thrombosis. Earlier reported incidence of PVTT in HCC was 34\% to 50\%, which is similar to this study $[33,34]$. The frequency of bland PVT in this study is also congruent with previous published studies $[35,36]$. The distribution of neoplastic thrombus within portal vein tributaries in this study is also comparable with earlier study [29].

Hepatocellular carcinoma patients with and without thrombotic complications were compared for major complications of underlying cirrhosis. Oesophageal varices, upper Gl bleeding, and ascites were more common in patients of HCC with PVTT and bland PVT having statistical significance ( $p<0.05$ for each). More variceal bleeding in HCC patients with thrombotic complication can be explained by higher pressure in the portal district, which is due to tumour invasion and portal hypertension. Previously published studies have also shown more variceal bleeding in HCC patients with thrombotic complication [37, 38]. Ascites, hepatorenal syndrome, and hepatic encephalopathy were more common complications among patients of HCC with PVTT and bland portal vein thrombosis. The above complications were found to be statistically significant ( $p<0.05$ for each) in the present study. The increased frequency of all the above complications can be explained by increased portal pressure in the case of HCC with thrombotic complication. Prior studies on the subject have shown increased hepatic venous pressure gradient (HVPG) in HCC patients, which is similar to this study $[39,40]$. Extra-hepatic metastases have been reported in $40 \%$ of cases of HCC at the time of their diagnosis [41]. Earlier studies have reported that HCC with tumour thrombus had more metastatic disease [42, 43]. This study is comparable to the above-mentioned studies because it has shown more metastatic disease in patients of HCC with tumour thrombosis and was found to be statistically significant $(p<0.05)$.

Various risk factors like advanced age, gender, tumour size, and stage of HCC were identified and studied as risk factors for PVTT. Connolly et al. in their study have shown advanced age, severe stage of cirrhosis (higher CTP), hypoalbuminaemia, some large vessel involvement, and raised AFP levels as predictors for PVTT in patients with HCC [44]. This study is in agreement with Connolly et al. and also showed advanced age, gender, tumour size, tumour morphology, higher CTP, and advanced stage of HCC as risk factors for PVTT. Pirisi et al. also identified female gender and advanced age as risk factors for tumour thrombosis in HCC patients [45]. Although above risk factors had a clear and distinctive association for thrombotic complications however It is noticeable in this study that most of the patients of HCC among non thrombotic group also had intermediate tumor size, tumor infiltration, Okuda stage (II) and advance cirrhosis (CTP-B, CTP-C) but has shown indistinctive association as risk factors for thrombotic complications in HCC. Viral aetiology versus non-viral was not identified to be a significant risk factor for tumour invasion in the current study and remains statistically insignificant, which is comparable to an earlier local study [28]. The limitation of the present study is not finding out the consequence of thrombotic complication on overall survival outcome of HCC, which is due to a lack of availability of all treatment modalities for HCC patients.

Thrombotic complications were defined on a radiological basis only. Hence macrothrombotic complications in reference to CT-scan findings were solely mentioned in the study, while pathological or microthrombotic complications were not assessed due to the need of invasive biopsy.

\section{Conclusions}

Cirrhosis due to HCV and HBV is a rampant problem in this part of the world. HCC is commonly found in cirrhosis and mainly involves the right lobe of the liver, which is multifocal in distribution. Thrombotic complication is also found frequently in these patients, which is mainly due to tumour thrombosis rather than bland portal vein thrombosis, and it makes overall prognosis bleak. Oesophageal varices with upper Gl bleeding, ascites, and hepatic encephalopathy are more common in patients having HCC with thrombotic complication. Advanced age, gender, size of the tumour, morphology of tumour, higher CTP, and advanced stage of HCC are important risk factors for thrombotic complication. Ignorance by the patients, financial problems, and lack of facilities adds further delay in early diagnosis of HCC, further escalating to morbidity and mortality.

\section{Conflict of interest}

The authors declare no conflict of interest. 


\section{References}

1. Forner A, Llovet JM, Bruix J. Hepatocellular carcinoma. Lancet 2012; 379: 1245-55

2. Ferlay J, Shin HR, Bray F, et al. Estimates of worldwide burden of cancer in 2008: GLOBOCAN 2008. Int J Cancer 2010; 127 : 2893-917.

3. Yang JD, Roberts LR. Hepatocellular carcinoma: a global view. Nat Rev Gastroenterol Hepatol 2010; 7: 448-58.

4. Bruix J, Sherman M; American Association for the Study of Liver Diseases. Management of hepatocellular carcinoma: an update. Hepatology 2011; 53: 1020-2.

5. Raza SA, Clifford GM, Franceschi S. Worldwide variation in the relative importance of hepatitis $B$ and hepatitis $C$ viruses in hepatocellular carcinoma: a systematic review. Br J Cancer 2007; 96: 1127-34.

6. Toyoda H, Kumada T, Kiriyama S, et al. Characteristics and prognosis of patients in Japan with viral marker-negative hepatocellular carcinoma. J Gastroenterol Hepatol 2008; 23: 459-66.

7. Liu CJ, Kao JH. Hepatitis B virus-related hepatocellular carcinoma: epidemiology and pathogenic role of viral factors. J Chin Med Assoc 2007; 70: 141-5.

8. Dohmen K, Shigematsu H, Irie K, et al. Comparison of the clinical characteristics among hepatocellular carcinoma of hepatitis $B$, hepatitis $C$ and non- $B$ non-C patients. Hepatogastroenterology 2003; 50: 2022-7.

9. Takizawa D, Kakizaki S, Sohara N, et al. Hepatocellular carcinoma with portal vein tumor thrombosis: clinical characteristics, prognosis, and patient survival analysis. Dig Dis Sci 2007; 52: 3290-5.

10. Sakata J, Shirai Y, Wakai T, et al. Preoperative predictors of thrombotic complication in hepatocellular carcinoma. Eur J Surg Oncol 2008; 34: 900-5.

11. Cheung TK, Lai CL, Wong BC, et al. Clinical features, biochemical parameters, and virological profiles of patients with hepatocellular carcinoma in Hong Kong. Aliment Pharmacol Ther 2006; 24: 573-83.

12. Minagawa M, Makuuchi M. Treatment of hepatocellular carcinoma accompanied by portal vein tumor thrombus. World J Gastroenterol 2006; 12: 7561-7.

13. Pirisi M, Avellini C, Fabris C, et al. Portal vein thrombosis in hepatocellular carcinoma: age and sex distribution in an autopsy study. J Cancer Res Clin Oncol 1998; 124: 397-400.

14. Schöniger-Hekele M, Müller C, Kutilek M, et al. Hepatocellular carcinoma in Central Europe: prognostic features and survival. Gut 2001; 48: 103-9.

15. Khokhar N, Aijazi I, Gill ML. Spectrum of hepatocellular carcinoma at Shifa International Hospital, Islamabad. J Ayub Med Coll Abbottabad 2003; 15: 1-4.

16. Tong CY, Khan R, Beeching NJ, et al. The occurrence of hepatitis $B$ and $C$ viruses in Pakistani patients with chronic liver disease and hepatocellular carcinoma. Epidemiol Infect 1996; 117: 327-32

17. Naqvi IH, Mahmood K, Salekeen S, et al. Determining the frequency and severity of malnutrition and correlating it with the severity of liver cirrhosis. Turk J Gastroenterol 2013; 24: 415-22.
18. Cantarini MC, Trevisani F, Morselli-Labate AM, et al. Effect of the etiology of viral cirrhosis on the survival of patients with hepatocellular carcinoma. Am J Gastroenterol 2006; 101: 91-8.

19. Hussain K, El-Serag HB. Epidemiology, screening, diagnosis and treatment of hepatocellular carcinoma. Minerva Gastroenterol Dietol 2009; 55: 123-38.

20. Dohmen K. Many staging systems for hepatocellular carcinoma: evolution from Child-Pugh. Okuda to SLiDe. J Gastroenterol Hepatol 2004; 19: 1227-32.

21. Trevisani F, De NS, Rapaccini G, et al. Semiannual and annual surveillance of cirrhotic patients for hepatocellular carcinoma: effects on cancer stage and patient survival (Italian experience). Am J Gastroenterol 2002; 97: 734-44.

22. Shah ZK, McKernan MG, Hahn PF, et al. Enhancing and expansile portal vein thrombosis: value in the diagnosis of hepatocellular carcinoma in patients with multiple hepatic lesions. AJR Am J Roentgenol 2007; 188: 1320-3.

23. Ho VB, Allen SF, Hood MN, et al. Renal masses: quantitative assessment of enhancement with dynamic MR imaging. Radiology 2002; 224: 695-700.

24. Pyrsopoulos N, Reddy RK. Hepatocellular carcinoma in Asia. In: Hepatitis B and C. Carrier to Cancer. Sarin SK, Okuda K (eds). Elsevier Sciences, India 2002; 363-4.

25. Sarin SK, Thakur V, Guptan RK, et al. Profile of hepatocellular carcinoma in India: an insight into the possible etiologic associations. J Gastroenterol Hepatol 2001; 16: 666-73.

26. Bosch FX. Global epidemiology of hepatocellular carcinoma. In: Liver Cancer. Okuda K, Tabor E (eds.). Churchill Livingstone, New York, 1997; 13-27.

27. Oka H, Kurioka N, Kim K, et al. Prospective study of early detection of hepatocellular carcinoma in patients with cirrhosis. Hepatology 1990; 12: 680-7.

28. Butt AS, Hamid S, Wadalawala AA, et al. Hepatocellular carcinoma in Native South Asian Pakistani population; trends, clinico-pathological characteristics and differences in viral marker negative and viral-hepatocellular carcinoma. BMC Research Notes 2013; 6: 137

29. Kumar R, Saraswat MK, Sharma BC, et al. Characteristics of hepatocellular carcinoma in India: a retrospective analysis of 191 cases. QJM 2008; 101: 479-85.

30. Toyoda H, Kumada T, Kiriyama S, et al. Characteristics and prognosis of patients in Japan with viral marker-negative hepatocellular carcinoma. J Gastroenterol Hepatol 2008; 23: 459-66.

31. Demirjian A, Peng P, Geschwind JF, et al. Infiltrating hepatocellular carcinoma: seeing the tree through the forest. J Gastrointest Surg 2011; 15: 2089-97.

32. Greten TF, Papendorf F, Bleck JS, et al. Survival rate in patients with hepatocellular carcinoma: a retrospective analysis of 389 patients. Br J Cancer 2005; 92: 1862-8.

33. The Cancer of the Liver Italian Program (CLIP) Investigators. Prospective validation of the CLIP score: a new prognostic system for patients with cirrhosis and hepatocellular carcinoma. Hepatology 2000; 31: 840-5.

34. Park KW, Park JW, Choi J, et al. Survival analysis of 904 patients with hepatocellular carcinoma in a hepatitis B virus-endemic area. J Gastroenterol Hepatol 2008; 23: 467-73. 
35. Garcia-Pagan JCGM, Bosch J. Obstruction of the portal vein. Blackwell, Oxford, England 2007.

36. op den Winkel M, Nagel D, Sappl J, et al. Prognosis of patients with hepatocellular carcinoma. Validation and ranking of established staging-systems in a large Western HCC-Cohort. PLoS One 2012; 7: e45066.

37. Chen CH, Sjeu JC, Huang GT, et al. Characteristics of hepatocellular carcinoma presenting with variceal bleeding. J Gastroenterol Hepatol 1998; 13: 170-4.

38. Lang BH, Poon RT, Fan ST, et al. Outcomes of patients with hepatocellular carcinoma presenting with variceal bleeding. Am J Gastroenterol 2004; 99: 2158-65.

39. Tandon P, Garcia-Tsao G. Portal hypertension and hepatocellular carcinoma: prognosis and beyond. Clin Gastroenterol Hepatol 2006; 4: 1318-9.

40. Giannini EG, Risso D, Testa R, et al. Prevalence and prognostic meaning of the presence of oesophageal varices in patients with hepatocellular carcinoma. Clin Gastroenterol Hepatol 2006; 4: 1378-84.

41. Si MS, Amersi F, Golish SR, et al. Prevalence of metastases in hepatocellular carcinoma: risk factors and impact on survival. Am Surgeon 2003; 69: 879-85.

42. Quirk M, Kim YH, Saab S, et al. Management of hepatocellular carcinoma with portal vein thrombosis. World J Gastroenterol 2015; 21: 3462-71.

43. Kanda M, Tateishi R, Yoshida H, et al. Extrahepatic metastasis of hepatocellular carcinoma: incidence and risk factors. Liver Int 2008; 28: 1256-63.

44. Connolly GC, Chen R, Hyrien O, et al. Incidence, risk factors and consequences of portal vein and systemic thromboses inhepatocellular carcinoma. Thromb Res 2008; 122: 299-306.

45. Pirisi M, Avellini C, Fabris C, et al. Portal vein thrombosis in hepatocellular carcinoma: age and sex distribution in an autopsy study. J Cancer Res Clin Oncol 1998; 124: 397-400.

Received: 12.02 .2017

Accepted: 16.06 .2017 